\title{
Review of Personalised Ventilation Programmes and Changes in Pressure Support Over Time in Patients with MND/ALS
}

\author{
Rogers $\mathrm{C}^{1 *}$, Oliver $\mathrm{D}^{2}$, Martin $\mathrm{K}^{1}$, Kindred $\mathrm{J}^{1}$ and Banerjee $\mathrm{S}^{1}$ \\ ${ }^{1}$ Medway NHS Trust, Gillingham, United Kingdom \\ ${ }^{2}$ University of Kent, Canterbury, United Kingdom \\ *Correspondence to: Charlotte Rogers, Medway NHS Trust, Windmill Road, Gillingham, Kent ME7 5NY, United Kingdom; Email: charlotte.rogers2@nhs.net
}

Received: December 09, 2017 Accepted: December 15, 2017; Published: December 15, 2017;

\section{Mini Review}

\section{Background}

Breathlessness and respiratory muscle weakness are key issues to manage in motor neurone disease (MND). As more is understood about this condition, more patients are being referred for and commenced on non-invasive ventilation (NIV) as a supportive tool [1]. Research is looking at the impact on general well-being, physical and mental health of this population group on NIV and appears to improve quality of life [2,3]. At Medway Maritime Hospital, patients are reviewed in a multi-disciplinary clinic including a respiratory consultant, specialist ventilation nurse and palliative care consultant. Therapy is targeted on ventilation methods to maximise activities of daily living, quality of life and easing symptoms. This includes the ventilation mode AVAPS-AE (average volume assured pressure support-auto end positive airway pressure) which will allow more control over both pressure and volume delivered and using hand-held and mouthpiece ventilators for more mobile ventilation.

\section{Objectives}

A review of patients' perceived quality of life and the impact of non-invasive ventilation on this. Also, a review of pressure support (PS) requirements of patients on our newer ventilation mode AVAPS$\mathrm{AE}$ and whether there is a change in the amount of this over time.

\section{Methods}

\section{Quality of life review.}

All 5 current patients with MND requiring NIV in April 2016 were sent a patient satisfaction survey and a shortened quality of life questionnaire based on the Short Form-36, looking at general health and bodily pain. The key sections included self-rating on their general health, limitations on daily activities and effects on physical health. These could not be scored using the standard scoring system due to its shortened nature and therefore the results were directly compared to one another.

\section{Review of pressure support requirements on AVAPS-AE.}

Data of all patients with MND requiring NIV usage on AVAPSAE mode over the past 3 years were reviewed. Data of the 5 patients on AVAPS-AE for over 6 months was collected, looking at average PS levels and usage per day over 3 month periods until April 2016.

\section{Results}

\section{Quality of life review}

Three out of 5 patients with MND requiring NIV responded to the patient survey. Each patient had been on domiciliary NIV for at least 1 year, with $2 / 3$ of patients' usage increasing every 6 months. The results showed that patients felt satisfied with their NIV, feeling their machine matched their everyday needs. Patient used different devices including hand-held, mouthpiece and facemask breathing devices. Despite NIV they felt their health had worsened and they all expected their health to get worse. Their health limited all of them in vigorous and moderate activities, climbing any number of flights of stairs and in bending, kneeling or stooping. Bodily pain was an increasing issue as the years of NIV usage increased, going from mild to moderate to severe for each increased year of NIV usage as was anxiety.

\section{Review of pressure support requirements on AVAPS-AE}

Of the 4 patients on a prolonged use of AVAPS-AE (over 6 months), 3 out of 4 saw an increase in PS requirements over time (range $0.7-7.4 \mathrm{cmH}_{2} \mathrm{O}$ ). All patients saw a gradual increase in average NIV usage hours per day. The increase was predominantly short bursts, which progressed to prolonged usage over the daytime.

\section{Discussion}

Breathlessness is a difficult symptom to manage and individualized therapy plans are important to effectively manage each case. Anxiety and expectations over declining physical function must be tackled as well as the physical respiratory muscle weakness [4]. Mouthpiece and hand-held devices appear to help to provide a patient with more autonomy and freedom from NIV as the disease progresses. 
We have shown that the number of NIV usage hours steadily increases as the disease progresses. It appears that the amount of pressure support increases over time, although more patient numbers are required to illustrate this to any statistical significance. AVAPS$\mathrm{AE}$ is a useful mode to safely provide increasing pressure support in the community as higher pressure levels can be delivered according to patient demand without the need for regular checks on patients' ventilators. This allows patients more time out of a hospital setting and further work will be required to assess the impact on patients' quality of life.

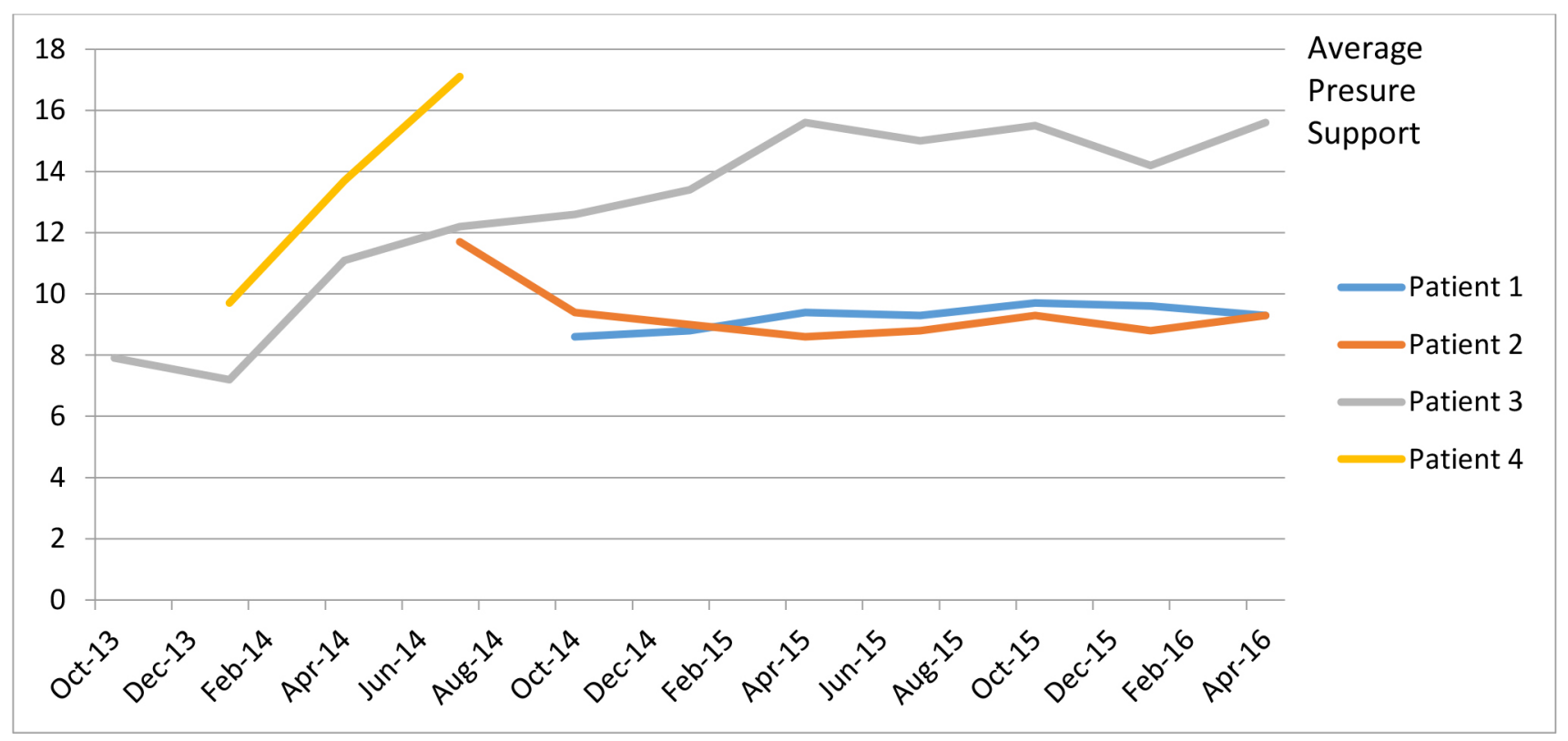

Figure 1. Average PS changes over time for individual patients

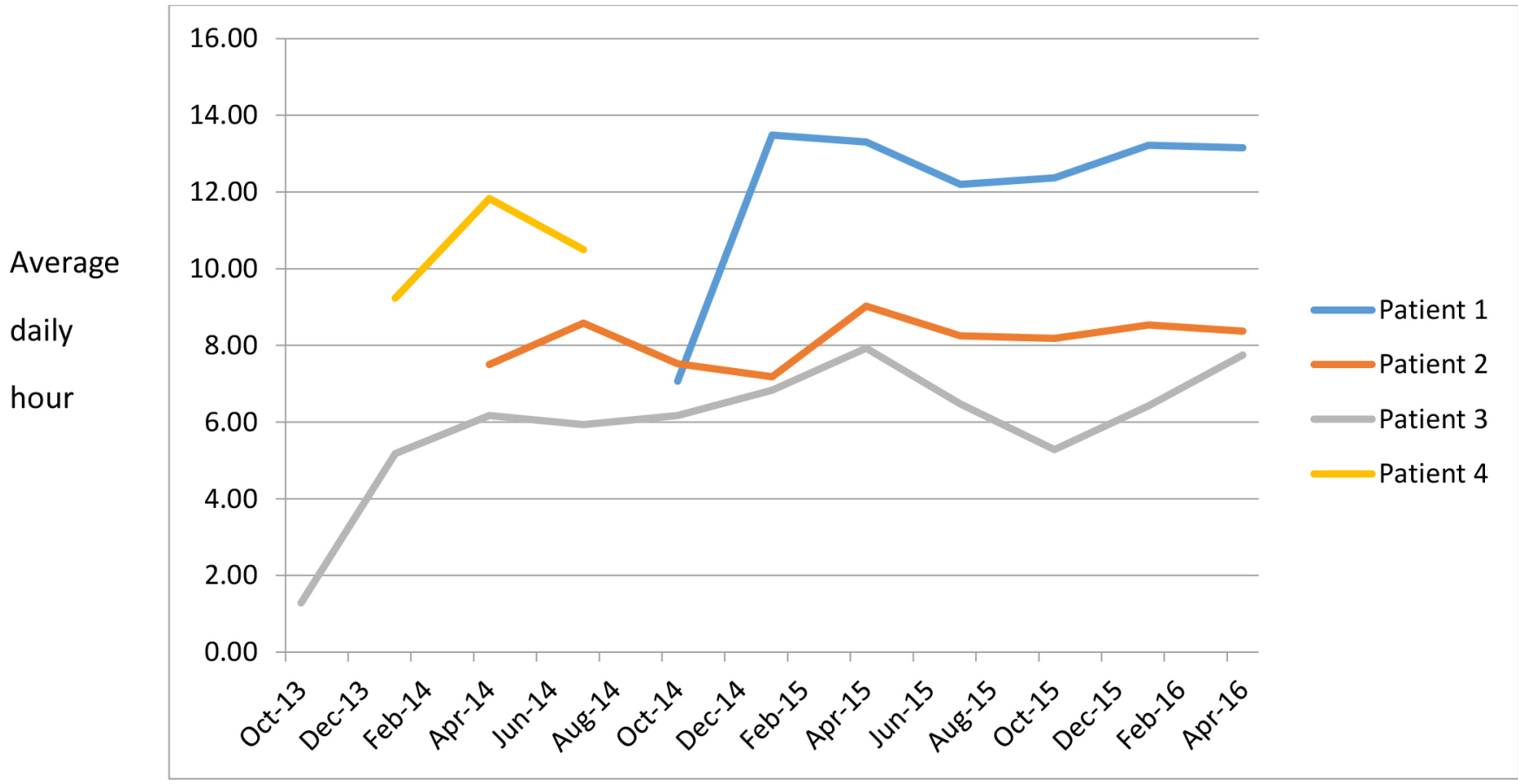

Figure 2. Average daily hour usage over time for individual patients 


\section{References}

1. Ando H, Williams C, Angus RM, Thornton EW, Chakrabarti B, et al. (2015) Why don't they accept non-invasive ventilation?: Insight into the interpersonal perspectives of patients with motor neurone disease. Br J Health Psychol 20: 341359. [crossref]

2. R McConigley, Kristjanson LJ, Aoun SM, Oldham L, Currow DC et al. (2014) Staying just one step ahead: providing care for patients with motor neurone disease. BMJ Support Palliat Care 4: 38-42. [crossref]

3. Lyall RA, Donaldson N, Fleming T, Wood C, Newsom-Davis I, et al. (2001) A prospective study of quality of life in ALS patients treated with noninvasive ventilation. Neurology 57:153-156. [crossref]

4. Oliver D, Radunovic A, Allen A, McDermott C (2017) The development of the UK National Institute of Health and Care Excellence evidence-based clinical guidelines on motor neurone disease. Amyotroph Lateral Scler Frontotemporal Degener 18: 313-323. [crossref] 